\title{
The shape of the halogen atom-anisotropy of electron distribution and its dependence on basis set and method used
}

\author{
Barbara Bankiewicz $\cdot$ Marcin Palusiak
}

Received: 28 September 2012/ Accepted: 20 October 2012/Published online: 9 November 2012

(C) The Author(s) 2012. This article is published with open access at Springerlink.com

\begin{abstract}
A search through Crystal Structure Database was performed and the distances in contacts of $\mathrm{X} \cdots \mathrm{N}, \mathrm{O}$, $\mathrm{X} \cdots \mathrm{H}(\mathrm{N}, \mathrm{O})$, and $\mathrm{X} \cdots \mathrm{C}$ type were collected together with the information on spatial arrangement of the interacting fragments. A detailed statistical analysis showed that the shape of the halogen atom cannot be simply concluded on the basis of interatomic distances in crystal state although originally the concept of anisotropic charge distribution around halogen nuclei was postulated on the basis of such an analysis. It was proven that the conclusions in that case strongly depend on the type of center interacting with the halogen atom. Therefore, it was postulated that the shape of the halogen atom can be estimated for the unperturbed (due to intermolecular interactions) halogen atom. For this purpose, a method was provided to make possible a numerical quantification of the anisotropy of the halogen atom on the basis of electron density measurements performed within the framework of Atoms in Molecules Quantum Theory. The anisotropy of $\mathrm{Cl}$ and $\mathrm{Br}$ atoms in $\mathrm{H}_{3} \mathrm{C}-\mathrm{X}$ and $\mathrm{F}_{3} \mathrm{C}-\mathrm{X}(\mathrm{X}=\mathrm{Cl}, \mathrm{Br})$ was estimated for MP2 and DFT-B3LYP methods and several different basis sets. The influence of the method and the basis set on the degree of anisotropic distribution of electron density around halogen nuclei was discussed.
\end{abstract}

Keywords Halogen bond - The shape of the atom . QTAIM · DFT · MP2 · Basis set

\footnotetext{
B. Bankiewicz

Department of Theoretical Chemistry, University of Białystok, Hurtowa 1, 15-399 Białystok, Poland

M. Palusiak ( $\square)$

Department of Theoretical and Structural Chemistry, University of Łódź, Tamka 12, 91-403 Łódź, Poland e-mail: marcinp@uni.lodz.pl
}

\section{Introduction}

Among different noncovalent interactions, the halogen bond (X-bond) attracts particular attention of researchers because, similarly as the hydrogen bond (H-bond), it is responsible for physical, chemical, and biologic properties of a large group of chemical species [1-16]. The X-bond is of the strength close to that of H-bond [1] and is strongly directional [17]. Thus, it is not only strong enough to bind molecules into larger complexes of stable structure but it also weak enough to be easily broken in experimental conditions or due to the processes occurring in living organisms. For this reason, X-bond is considered as an interaction which can play an important role in crystal engineering [18], drug design [16, 19], and new material engineering [20]. The mechanism of formation of X-bond seems to be well known. It has been generally accepted that due to anisotropy of halogen atoms, the partial positive charge occurs in the region of halogen valence sphere being placed opposite to the covalent bond linking the halogen atom with its adjacent atom (usually it is the carbon atom or another halogen atom, but not the hydrogen atom). This partial positive charge on the valence sphere of the halogen atom is often defined within the framework of NBO theory [21] as a sigma hole - a local deficit of an electron charge (a hole) being placed opposite the sigma bond $[22,23]$. The sigma hole may interact with the local electron charge surplus such as lone electron pairs [17, 24, 25], pi-type electrons [17, 24, 26], or even sigma-type electrons [27]; in this way, the mechanism of formation of X-bond can be well defined. However, there are some discrepancies regarding the nature of X-bonding. The sigma hole can be visualized graphically by the electrostatic potential projected on the electron density isosurface $[16,19]$. As a result, the electrostatic nature of $\mathrm{X}$-bonding was proposed 
[17]. However, in the literature, there are several reports based on the different interaction energy decompositions, in which it was shown that not necessarily electrostatic interaction, but HOMO-LUMO charge transfer and polarization [28], induction, and/or dispersion [27, 29, 30] are responsible for X-bonding. Unfortunately, each type of the interaction energy decomposition is always connected with an arbitrary procedure, and the components of interaction energy obtained within the framework of different schemes are often incomparable. What is more, it should be expected that depending on the physical and/or chemical conditions, the nature of X-bonding may vary, which additionally complicates the situation. For this reason, the final agreement regarding the nature of X-bonding has probably not been reached yet. Undoubtedly, the anisotropy of halogen atoms is considered as the phenomenon which directly lays the foundations of $\mathrm{X}$-bond formation.

To the best of our knowledge, the first report on anisotropy of halogen atoms was published by Nyburg and Faerman in 1985 [31]. On the basis of statistical analysis of data collected in Crystal Structure Database (CSD) [32], it was reported that the shape of halogen atoms "...is more or less spheroidal, always having the shorter radius along the atom-to-carbon bond vector (polar flattering)." Such a conclusion was drawn after the analysis of interatomic distances in crystals. Later, in 1994, Price et al. [33] were investigating the nature of $\mathrm{R} 1-\mathrm{Cl} \cdots \mathrm{Cl}-\mathrm{R} 2$ interactions; on the basis of the analysis of $\mathrm{Cl} \cdots \mathrm{Cl}$ distances in crystals and also on the basis of quantum-chemical calculations they concluded that such interactions were stabilizing, but what is particularly important, for the first time the phenomenon of anisotropic charge distribution around halogen nuclei was directly linked with the phenomenon of the $\mathrm{Cl} \cdots \mathrm{Cl}$ noncovalent bonding. (Note that due to the same mechanism of formation, the $\mathrm{Cl} \cdots \mathrm{Cl}$ interaction can be considered as a specific type of $\mathrm{X}$-bonding; however, the term "dihalogen bond" is also often used for such type of interactions to distinguish them from typical X-bonds (e.g., $\mathrm{R}-\mathrm{X} \cdots \mathrm{N}, \mathrm{O})$ [34]. Finally, in 1996, Lommers et al. [29] performed a detailed analysis of geometrical and energetic parameters of $\mathrm{Cl} \cdots \mathrm{O}$ and $\mathrm{Cl} \cdots \mathrm{N} \mathrm{X}$-bonds and explained the mechanism of formation and the directionality of such an interaction by means of the concept of anisotropic electron distribution around the halogen atom. It is worth pointing out that these reports, being fundamental to the knowledge of X-bond, were prepared on the basis of the search through CSD. What is important, in each case, the anisotropic shape of the halogen atom was concluded after the analysis of distances between the halogen atom and another atomic center always having lone electron pairs. Thus, assuming anisotropic charge distribution around halogen nuclei, the atomic center possessing lone electron pairs is not a neutral probe with respect to the halogen atom. In other words, when such an atomic center approaches the halogen atom in the direction of the sigma hole, the attraction between both centers occurs (that is, between the lone electron pair and the sigma hole); whereas, when such a center approaches the halogen atom in the direction being perpendicular to the previous one, there is an additional repulsion between the two regions of electron density concentrations. When the non-neutral probe is used for the assessment of the halogen atom anisotropy, the observed result can be additionally amplified due to the directional character of attraction and repulsion between the interacting fragments. Therefore, it is interesting to know how far the anisotropic charge distribution can in fact be observed for the unperturbed halogen atom in a molecule. Very recently the anisotropy of several various atoms was estimated by means of integrations over stockholder atoms, and on that basis the anisotropy of halogen atoms was confirmed [35]. However, the estimated anisotropy of, e.g., $\mathrm{Cl}$ atom in $\mathrm{HCl}$ molecule was smaller than in the case of $\mathrm{Si}$ atom in $\mathrm{SiH}_{4}$ molecule $\left(30.2 \times 10^{-3}\right.$ and $59.2 \times 10^{-3}$, respectively). What is more, such an integration does not provide information on the directionality of the anisotropy itself, which, as a phenomenon, is directly responsible for X-bond formation. For this reason, we decided to take an effort to quantify the anisotropy of halogen atoms in molecules that are often used as model systems in the studies on X-bonding. We also wanted to show that depending on the probing center used in the search through CSD, the anisotropy of the halogen atom can be more or less efficient. Finally, our aim was to test how far the anisotropy of the halogen atom might depend on the basis set used for calculations. For the purpose of such an analysis, we provide a simple method which gives the possibility of the quantification of anisotropy.

\section{Methodology}

To study the degree of anisotropic distribution of electron density around halogen nuclei with respect to the method and the basis set, the following molecular models were chosen: chloromethane, bromomethane, trifluoromethyl chloride, and trifluoromethyl bromide.

All calculations were carried out by means of the Gaussian 09 suite of programs [36, 37]. Molecules were optimized by means of the hybrid functional of Becke with Lee, Yang and Parr gradient correction (B3LYP) $[38,39]$ and the second-order Møller-Plesset perturbation theory (MP2) $[40,41]$ levels of theory. In addition, the two types of MP2 calculations were considered, the MP2 using the SCF densities, and MP2 using the post-SCF densities.

For all methods, the number of different basis sets was tested, starting from the minimal 3-21G basis set, through the medium, and finally the large basis sets of Pople and 
Dunning type (For the original references to all basis sets, see Gaussian 09 references list available online [37, 42]) and finishing with the augmented correlation-consistent Dunning-type basis set of the valence-split triple- $\xi$ quality (augcc-pVTZ) combined with the pseudo core potential [42] in the place of the halogen atom's nuclei and core density.

All analyzed systems were optimized without any restrictions as to their starting geometries. However, it was requested that the structures of final molecules have a specific spatial orientation, where the covalent bond $\mathrm{C}-\mathrm{X}$ $(\mathrm{X}=\mathrm{Cl}, \mathrm{Br}$ ) was situated longwise one of Cartesian axes to make it easier to quantify the halogen atoms anisotropy. (This procedure is presented in detail in the next section of the article). The frequency calculations were performed to verify whether the obtained geometries correspond to the minima on the potential energy surface or not. No imaginary frequencies were found.

The analysis of the electron distribution function was performed with the AIM2000 [43, 44] program by means of the PROAIMS formatted wavefunction files, produced at the same level of theory as the geometry optimization was done.

\section{Results and discussion}

In our studies, we were interested in how far the halogen atom is characterized by anisotropic charge distribution. As mentioned in the introduction, the anisotropic charge distribution of the halogen atom was originally postulated on the basis of the distances between the halogen atom and the other atoms, such as $\mathrm{N}, \mathrm{O}$, or another halogen atom. What is important, the other atomic center always possessed the lone electron pairs, which means that it could act as the Lewis base. In this way, the probe used for the scan of the halogen atom surface was not a neutral one. In what follows, we repeat such an analysis using the $\mathrm{N}$ and $\mathrm{O}$ centers as probes (Note that the number of structures collected in CSD has increased significantly since the 1990s, which additionally increases the significance of the results obtained by means of statistical analysis). However, we enlarge our approach to include two additional types of centers considered as probes. We take an $\mathrm{H}$ atom attached to the $\mathrm{N}$ or $\mathrm{O}$ atom as the center which may act as a Lewis-type acid (the potential protondonating center). In addition, we search for contacts between the tested halogen atom and the $\mathrm{C}$ atom of any type, considering such a $\mathrm{C}$ atom as a center being more neutral in its nature than the $\mathrm{N}, \mathrm{O}$, or $\mathrm{H}(\mathrm{N}, \mathrm{O})$ probes.

The search was performed using the following criteria:

1. The main criterion was the presence of the contact between the halogen atom $\mathrm{X}$ attached to carbon atom $\mathrm{C}$ and the atomic center considered as a probe and denoted as Y. See Scheme 1 for graphic representation. The $\mathrm{X} \cdots \mathrm{Y}$ distance was defined as being shorter than the sum of vdW radii $+0.3 \AA$. The vdW radii were declared as defaults in ConQuest, that is, $\mathrm{F}(1.47 \AA), \mathrm{Cl}(1.75 \AA), \mathrm{Br}(1.85 \AA), \mathrm{I}(1.98 \AA), \mathrm{C}(1.70 \AA)$, $\mathrm{N}(1.55 \AA), \mathrm{O}(1.52 \AA), \mathrm{H}(1.09 \AA)[45,46]$.

2. The carbon atom to which the halogen atom $X$ was attached was always of $\mathrm{sp}^{3}$ type (tetravalent).

3. Only data from structures of the highest quality were collected. We consider the given structure as one of the highest quality when it fulfills the following criteria: $R \leq 0.5$, not disordered, with no errors, not polymeric, with no ions or powder structures.

4. The $\mathrm{N}-\mathrm{H}$ and $\mathrm{O}-\mathrm{H}$ bond lengths were normalized.

From the search, we obtained a set of two spherical variables, that is, the $\mathrm{X} \cdots \mathrm{Y}$ distance, $|\vec{r}|$, and the angle $\varphi$ formed by vector $\vec{r}$ and the direction of the $\mathrm{C}-\mathrm{X}$ bond. Those two spherical variables can easily be changed on two Cartesian variables $x$ and $y$. In this way, we were able to obtain the distribution of points representing the position of the probe with respect to the halogen atom placed in the origin of $X$ axis (horizontal direction) and $Y$ axis (vertical direction). Figure 1 shows such a graphical representation. It is important to note that in this way, we keep the information about spatial orientation of the halogen $(\mathrm{X})$ and the probe $(\mathrm{Y})$ with respect to the $\mathrm{C}$ atom. In Fig. 1, the $Y$ axis is the elongation of the $\mathrm{C}-\mathrm{X}$ bond direction, which means that the points placed on that axis lie exactly on the elongation of the $\mathrm{C}-\mathrm{X}$ bond direction, being in an opposite position with respect to that of the $\mathrm{C}$ atom.

As it can be seen, the distance between the given halogen atom and the interacting center (the probe) depends

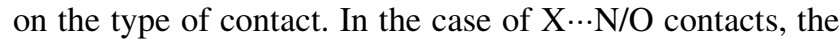
anisotropy of distribution of points can be clearly seen in the case of heavier $\mathrm{X}$ atoms, with a maximum for iodine, where the shortest distances on elongation of the $\mathrm{C}-\mathrm{X}$ bond ( $Y$ axis) are of around $2.7 \AA$, whereas the shortest distances in the direction perpendicular to the $\mathrm{C}-\mathrm{X}$ bond ( $\mathrm{X}$ axis) are

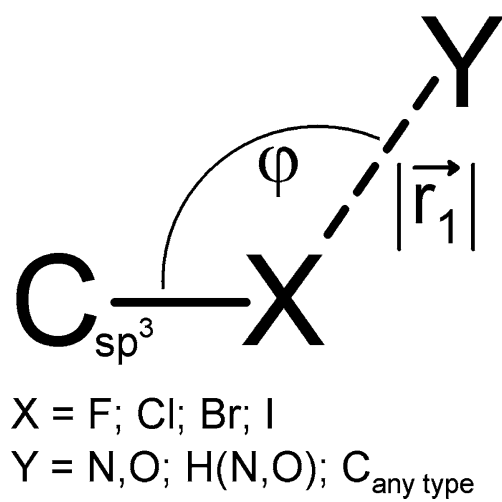

Scheme 1 The main criteria used for the search through CSD 

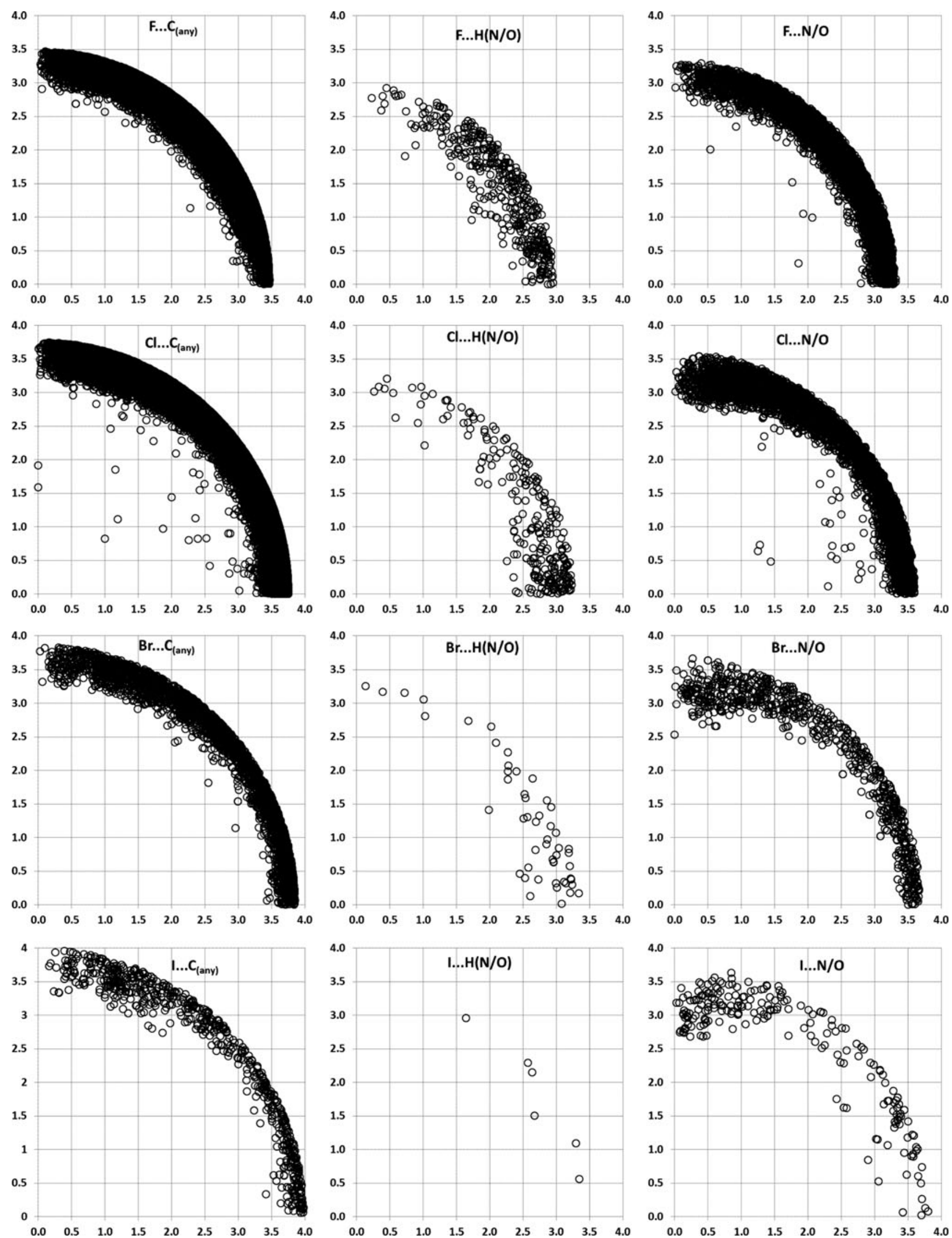
4 Fig. 1 A graphical representation of the spatial arrangement between $\mathrm{C}-\mathrm{X}$ bond and the $\mathrm{Y}$ atom being a probe. Note that the $\mathrm{Y}$ axis (vertical direction) is the elongation of $\mathrm{C}-\mathrm{X}$ bond direction, whereas the $\mathrm{X}$ axis (horizontal direction) is perpendicular to $\mathrm{C}-\mathrm{X}$ bond direction. The position of $\mathrm{X}$ atom is in the $\mathrm{XY}$ origin. All diagrams are scaled in the same scale

of around $3.4 \AA$. Interestingly, for $\mathrm{X}=\mathrm{Br}$ and $\mathrm{X}=\mathrm{Cl}$, these dependences are practically the same with only slightly shorter contacts in the $\mathrm{X}$ direction for $\mathrm{X}=\mathrm{Cl}$. For $\mathrm{X}=\mathrm{F}$ such anisotropy in points distribution cannot be observed and the distances in all directions are close to $2.8 \AA$. Therefore, basing on $\mathrm{N}$ and $\mathrm{O}$ as probes, the anisotropy of heavier halogen atoms can be established. There is only one exception, namely fluorine. Note that $F$ seldom forms $\mathrm{X}$-bonds, if at all [17, 24, 27]. Our results are in agreement with some earlier works, going back to Nyburg and Faerman [31] who, for instance, proposed an effective elliptical shape of the $\mathrm{Cl}$ atom with a minor radius of $1.58 \AA$ and a major radius of $1.78 \AA$. Assuming spherical shape of both $\mathrm{N}\left(r_{\mathrm{N}}=1.55 \AA\right)$ and $\mathrm{O}\left(r_{\mathrm{O}}=1.52 \AA\right)$ [45] atoms, the same radii of the $\mathrm{Cl}$ atom can be deduced from Fig. 1.

Passing from the $\mathrm{X} \cdots \mathrm{N} / \mathrm{O}$ to $\mathrm{X} \cdots \mathrm{H}-(\mathrm{N} / \mathrm{O})$ contacts, in the case of $\mathrm{Cl}$ and $\mathrm{Br}$ atoms, the situation with anisotropic distribution of points in the diagram is reversed and this time shorter distances $(\sim 2.5 \AA)$ appear for the direction perpendicular to the $\mathrm{C}-\mathrm{X}$ bond ( $\mathrm{X}$ axis); whereas, in the direction of the $\mathrm{C}-\mathrm{X}$ bond ( $Y$ axis), the shortest distances are relatively longer $(\sim 3.0 \AA)$. For $\mathrm{X}=\mathrm{F}$ there is again an exception, and the shortest distances measured both in the $\mathrm{X}$ and $\mathrm{Y}$ directions are of the same length. Interestingly, in that case, the relatively shorter distances $(\sim 2.5 \AA)$ can be noticed in the $\mathrm{XY}$ (diagonal) direction, thus, in a direction corresponding to the position of lone pairs located on the $\mathrm{F}$ atom. It is also worth pointing out that in the case of $\mathrm{X}=\mathrm{Cl}$ and $\mathrm{Br}$ there is a concentration of points in the $\mathrm{X}$ direction, which can support the concept of anisotropic charge distribution around these atoms toward the elliptical shape, since, according to this concept, in that direction a surplus of electron charge should be observed. Looking at the number of populations of points in the diagrams a clear decrease of the number of points can be seen with the increase of halogen atom size. This is in line with general knowledge on H-bonding, according to which the protonaccepting properties of halogen atoms decrease with the increase of their size. In the case of $\mathrm{X}=\mathrm{I}$, merely seven contacts fulfilled the criteria of the search. Also, looking at Fig. 1 it can be said that, as compared with two other types of interactions, halogen atoms rather seldom form hydrogen bonds. This observation was earlier reported by Dunitz and Taylor [47].

Finally, in the case of $\mathrm{X} \cdots \mathrm{C}_{\mathrm{any}}$ contacts, no anisotropic distribution of points can be found although for $I \cdots C_{a n y}$ contacts some concentration of points in the direction corresponding to the $\mathrm{C}-\mathrm{I}$ bond elongation ( $Y$ axis) can be noticed.

Summarizing, it can be said that generally the virtual shape of the halogen atom, when deduced on the basis of distances between this atom and another interacting center, strongly depends on the type of contact. When the carbon atom, being most neutral of all those taken into account was considered as a probing center, the deduced shape of the halogen atom is rather spherical with no noticeable anisotropy in charge distribution. Thus, a question arises if the halogen atom has a spherical or an ellipsoidal shape? And, if it is ellipsoidal, then does this shape result from the influence of the interacting center? In the next part of our article, we give answers to these questions, analyzing the distribution of charge density in the undisturbed halogen atom in $\mathrm{H}_{3} \mathrm{C}-\mathrm{X}(\mathrm{X}=\mathrm{Cl}$ and $\mathrm{Br})$ model molecules.

In order to quantify the anisotropy of the halogen atom, we introduce a simple parameter denoted as $\chi$, which can be defined as follows:

$\chi=\frac{\left|r_{2}\right|-\left|r_{1}\right|}{\left|r_{1}\right|} \times 100 \%$

where $r_{1}$ is the vector of the arbitrary length corresponding to the van der Waals radii of the given halogen atom, the vector which is directed in the opposite direction with respect to the $\mathrm{C}-\mathrm{X}$ bond (see Fig. 2), whereas $r_{2}$ is the vector of length estimated in the direction perpendicular to the $r_{1}$ vector. The values of van der Waals radii were taken from Bondi [45] ( $r_{1}$ was 1.75 and $1.85 \AA$ for $\mathrm{Cl}$ and $\mathrm{Br}$, respectively). The length of $r_{2}$ was estimated on the basis of electron density distribution. First, the amount of electron density was measured at the end of the $r_{1}$ vector, and the electron density was scanned along the $r_{2}$ direction until the same value of electron density as that at the end of $r_{1}$ was found. This procedure is schematically illustrated in Fig. 2.

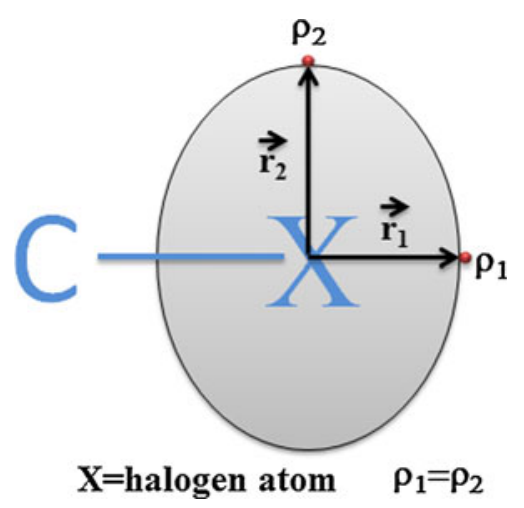

Fig. 2 Spatial interrelation between the $r_{1}$ and $r_{2}$ vectors used to define the $\chi$ parameter 
Table 1 Numerical data for $\mathrm{H}_{3} \mathrm{CCl}$ molecule (energy given in hartrees)

\begin{tabular}{|c|c|c|c|c|c|c|c|c|c|c|c|}
\hline & \multirow[t]{2}{*}{$\mathrm{NBF}$} & \multirow[t]{2}{*}{ NPrimitives } & \multicolumn{3}{|l|}{ B3LYP } & \multicolumn{3}{|c|}{ MP2 (SCF density) } & \multicolumn{3}{|c|}{ MP2 (post-SCF density) } \\
\hline & & & $E_{\text {tot }}$ & $r_{2}$ & $\chi$ & $E_{\text {tot }}$ & $r_{2}$ & $\chi$ & $E_{\text {tot }}$ & $r_{2}$ & $\chi$ \\
\hline $3-21 G$ & 28 & 51 & -497.6912 & 1.910 & 9.153 & -496.8298 & 1.898 & 8.437 & -496.8298 & 1.911 & 9.190 \\
\hline $3-21+\mathrm{G}$ & 36 & 59 & -497.7053 & 1.922 & 9.831 & -496.8429 & 1.905 & 8.881 & -496.8429 & 1.922 & 9.825 \\
\hline $6-31 G$ & 28 & 80 & -500.0818 & 1.893 & 8.158 & -499.1931 & 1.910 & 9.150 & -499.1931 & 1.924 & 9.961 \\
\hline $6-31 G(d)$ & 40 & 92 & -500.1085 & 1.922 & 9.819 & -499.3546 & 1.920 & 9.704 & -499.3546 & 1.917 & 9.562 \\
\hline $6-31 \mathrm{G}(2 \mathrm{~d})$ & 52 & 104 & -500.1085 & 1.921 & 9.791 & -499.3843 & 1.929 & 10.230 & -499.3843 & 1.920 & 9.716 \\
\hline $6-31 G(3 d f)$ & 78 & 136 & -500.1164 & 1.915 & 9.407 & -499.4417 & 1.938 & 10.729 & -499.4417 & 1.921 & 9.782 \\
\hline $6-31+\mathrm{G}$ & 36 & 88 & -500.0852 & 1.929 & 10.218 & -499.1965 & 1.929 & 10.218 & -499.1965 & 1.932 & 10.396 \\
\hline $6-31+G(d)$ & 48 & 100 & -500.1115 & 1.926 & 10.036 & -499.3575 & 1.925 & 10.024 & -499.3575 & 1.924 & 9.924 \\
\hline $6-31+G(2 d)$ & 60 & 112 & -500.1116 & 1.930 & 10.284 & -499.3871 & 1.936 & 10.602 & -499.3871 & 1.927 & 10.091 \\
\hline $6-31+G(3 d f)$ & 86 & 144 & -500.1192 & 1.922 & 9.825 & -499.4444 & 1.941 & 10.886 & -499.4444 & 1.926 & 10.042 \\
\hline $6-31++\mathrm{G}$ & 39 & 91 & -500.0852 & 1.930 & 10.260 & -499.1968 & 1.918 & 9.589 & -499.1968 & 1.933 & 10.475 \\
\hline $6-31++\mathrm{G}(\mathrm{d})$ & 51 & 103 & -500.1115 & 1.926 & 10.060 & -499.3578 & 1.927 & 10.100 & -499.3578 & 1.924 & 9.970 \\
\hline $6-31++\mathrm{G}(2 \mathrm{~d})$ & 63 & 115 & -500.1116 & 1.930 & 10.287 & -499.3874 & 1.936 & 10.641 & -499.3874 & 1.927 & 10.118 \\
\hline $6-31++G(3 d f)$ & 89 & 147 & -500.1192 & 1.922 & 9.813 & -499.4446 & 1.940 & 10.883 & -499.4446 & 1.926 & 10.033 \\
\hline $6-31++\mathrm{G}(3 \mathrm{df}, 3 \mathrm{pd})$ & 134 & 192 & -500.1238 & 1.924 & 9.936 & -499.4721 & 1.940 & 10.862 & -499.4721 & 1.926 & 10.060 \\
\hline $6-311 G$ & 43 & 84 & -500.1226 & 1.927 & 10.106 & -499.2412 & 1.915 & 9.404 & -499.2412 & 1.928 & 10.157 \\
\hline $6-311 \mathrm{G}(\mathrm{d})$ & 53 & 96 & -500.1465 & 1.920 & 9.689 & -499.4038 & 1.916 & 9.465 & -499.4038 & 1.913 & 9.301 \\
\hline $6-311 G(2 d)$ & 63 & 108 & -500.1488 & 1.926 & 10.073 & -499.4318 & 1.930 & 10.272 & -499.4318 & 1.918 & 9.613 \\
\hline $6-311 G(3 d f)$ & 87 & 140 & -500.1537 & 1.932 & 10.393 & -499.4882 & 1.947 & 11.231 & -499.4882 & 1.931 & 10.366 \\
\hline $6-311+\mathrm{G}$ & 51 & 92 & -500.1242 & 1.900 & 8.594 & -499.2442 & 1.928 & 10.172 & -499.2442 & 1.942 & 10.962 \\
\hline $6-311+\mathrm{G}(\mathrm{d})$ & 61 & 104 & -500.1477 & 1.928 & 10.184 & -499.4062 & 1.929 & 10.215 & -499.4062 & 1.924 & 9.958 \\
\hline $6-311+\mathrm{G}(2 \mathrm{~d})$ & 71 & 116 & -500.1496 & 1.932 & 10.426 & -499.4335 & 1.937 & 10.714 & -499.4335 & 1.925 & 10.012 \\
\hline $6-311+\mathrm{G}(3 \mathrm{df})$ & 95 & 148 & -500.1544 & 1.928 & 10.191 & -499.4896 & 1.944 & 11.107 & -499.4896 & 1.928 & 10.200 \\
\hline $6-311++\mathrm{G}$ & 54 & 95 & -500.1244 & 1.937 & 10.677 & -499.2446 & 1.928 & 10.181 & -499.2446 & 1.942 & 10.980 \\
\hline $6-311++\mathrm{G}(\mathrm{d})$ & 64 & 107 & -500.1478 & 1.929 & 10.236 & -499.4065 & 1.929 & 10.257 & -499.4065 & 1.925 & 10.003 \\
\hline $6-311++\mathrm{G}(2 \mathrm{~d})$ & 74 & 119 & -500.1497 & 1.933 & 10.466 & -499.4338 & 1.938 & 10.750 & -499.4338 & 1.926 & 10.051 \\
\hline $6-311++G(3 d f)$ & 98 & 151 & -500.1545 & 1.929 & 10.212 & -499.4898 & 1.945 & 11.122 & -499.4898 & 1.929 & 10.215 \\
\hline $6-311++\mathrm{G}(3 \mathrm{df}, 3 \mathrm{pd})$ & 140 & 196 & -500.1598 & 1.925 & 9.985 & -499.5136 & 1.939 & 10.804 & -499.5136 & 1.925 & 9.973 \\
\hline cc-pVDZ & 47 & 125 & -500.1285 & 1.899 & 8.503 & -499.4032 & 1.894 & 8.219 & -499.4032 & 1.894 & 8.225 \\
\hline maug-cc-pVDZ & 55 & 133 & -500.1332 & 1.918 & 9.610 & -499.4077 & 1.912 & 9.280 & -499.4077 & 1.912 & 9.268 \\
\hline aug-cc-pVDZ & 77 & 157 & -500.1360 & 1.912 & 9.247 & -499.4253 & 1.926 & 10.033 & -499.4253 & 1.918 & 9.598 \\
\hline cc-pVTZ & 106 & 197 & -500.1645 & 1.910 & 9.120 & -499.5202 & 1.914 & 9.398 & -499.5202 & 1.904 & 8.827 \\
\hline maug-cc-pVTZ & 114 & 205 & -500.1654 & 1.920 & 9.692 & -499.5212 & 1.925 & 10.021 & -499.5212 & 1.914 & 9.359 \\
\hline aug-cc-pVTZ & 165 & 267 & -500.1658 & 1.922 & 9.831 & -499.5292 & 1.931 & 10.318 & -499.5292 & 1.920 & 9.698 \\
\hline aug-cc-pVTZ with ECP & 165 & 267 & -54.8401 & 1.892 & 8.092 & -54.6953 & 1.904 & 8.800 & -54.6953 & 1.893 & 8.158 \\
\hline Mean value & & & & & 9.777 & & & 10.077 & & & 9.830 \\
\hline E.s.d. for mean value & & & & & 0.641 & & & 0.774 & & & 0.602 \\
\hline
\end{tabular}

Therefore, the only variable in Eq. 1 is the length of the $r_{2}$ vector. Since we used different methods and basis sets, this variable depends on the type of halogen atom and the quantum-chemical approximation used for the representation of this atom and its chemical surrounding. In Tables 1, 2,3 , and 4 the data collected for several different basis sets and methods can be found. Two chemistry models were used, DFT-B3LYP and MP2, in the case of the latter both SCF and post-SCF densities were tested. As can be seen from Tables 1, 2, 3, and 4, for all types of basis sets the anisotropy of the halogen atom can be confirmed. In the case of $\mathrm{Cl}$ atom, the values of anisotropy are of about 9-10\% with slightly larger mean $\chi$ values for $\mathrm{F}_{3} \mathrm{C}-\mathrm{Cl}$, as compared with $\mathrm{H}_{3} \mathrm{CCl}$. However, the difference is rather small, being of around $0.2 \%$ for mean $\chi$ values in the case of DFT calculations and only $0.05 \%$ in the case of MP2 post-SCF densities. These differences are even smaller if we compare the results of calculations made with the 
Table 2 Numerical data for $\mathrm{H}_{3} \mathrm{CBr}$ molecule (energy given in hartrees)

\begin{tabular}{|c|c|c|c|c|c|c|c|c|c|c|c|}
\hline & \multirow[t]{2}{*}{ NBF } & \multirow[t]{2}{*}{ NPrimitives } & \multicolumn{3}{|l|}{ B3LYP } & \multicolumn{3}{|c|}{ MP2 (SCF density) } & \multicolumn{3}{|c|}{ MP2 (post-SCF density) } \\
\hline & & & $E_{\text {tot }}$ & $r_{2}$ & $\chi$ & $E_{\text {tot }}$ & $r_{2}$ & $\chi$ & $E_{\text {tot }}$ & $r_{2}$ & $\chi$ \\
\hline $3-21 G$ & 38 & 81 & -2601.4975 & 2.029 & 9.662 & -2599.5794 & 2.020 & 9.193 & -2599.5794 & 2.026 & 9.53 \\
\hline $6-31 \mathrm{G}$ & 39 & 111 & -2611.4755 & 2.048 & 10.692 & -2609.4856 & 2.039 & 10.240 & -2609.4856 & 2.048 & 10.684 \\
\hline $6-31 G(d)$ & 51 & 123 & -2611.6166 & 2.049 & 10.738 & -2609.7448 & 2.049 & 10.732 & -2609.7448 & 2.040 & 10.260 \\
\hline $6-31 G(2 d)$ & 63 & 135 & -2611.7823 & 2.026 & 9.525 & -2609.9417 & 2.054 & 11.044 & -2609.9417 & 2.032 & 9.826 \\
\hline $6-31 G(3 d f)$ & 89 & 167 & -2611.6742 & 2.025 & 9.474 & -2609.8786 & 2.047 & 10.635 & -2609.8786 & 2.030 & 9.734 \\
\hline $6-31+\mathrm{G}$ & 47 & 119 & -2611.4932 & 2.061 & 11.416 & -2609.5032 & 2.050 & 10.784 & -2609.5032 & 1.992 & 7.65 \\
\hline $6-31+\mathrm{G}(\mathrm{d})$ & 59 & 131 & -2611.6324 & 2.067 & 11.705 & -2609.7601 & 2.063 & 11.530 & -2609.7601 & 2.054 & 11.015 \\
\hline $6-31+G(2 d)$ & 71 & 143 & -2611.7910 & 2.047 & 10.632 & -2609.9503 & 2.070 & 11.871 & -2609.9503 & 2.049 & $10.74 \mathrm{C}$ \\
\hline $6-31+G(3 d f)$ & 97 & 175 & -2611.6803 & 2.050 & 10.830 & -2609.8844 & 2.066 & 11.653 & -2609.8844 & 2.051 & 10.838 \\
\hline $6-31++\mathrm{G}$ & 50 & 122 & -2611.4951 & 2.059 & 11.316 & -2609.5053 & 2.047 & 10.669 & -2609.5053 & 2.059 & 11.273 \\
\hline $6-31++G(d)$ & 62 & 134 & -2611.6336 & 2.066 & 11.682 & -2609.7617 & 2.063 & 11.499 & -2609.7617 & 2.054 & 11.001 \\
\hline $6-31++\mathrm{G}(2 \mathrm{~d})$ & 74 & 146 & -2611.7915 & 2.047 & 10.624 & -2609.9511 & 2.069 & 11.811 & -2609.9511 & 2.048 & 10.727 \\
\hline $6-31++\mathrm{G}(3 \mathrm{df})$ & 100 & 178 & -2611.6808 & 2.051 & 10.881 & -2609.8850 & 2.066 & 11.691 & -2609.8850 & 2.051 & 10.870 \\
\hline $6-31++\mathrm{G}(3 \mathrm{df}, 3 \mathrm{pd})$ & 145 & 223 & -2611.6867 & 2.052 & 10.892 & -2609.9136 & 2.067 & 11.751 & -2609.9136 & 2.053 & 10.947 \\
\hline $6-311 \mathrm{G}$ & 61 & 125 & -2614.0081 & 2.063 & 11.487 & -2612.0852 & 2.059 & 11.299 & -2612.0852 & 2.065 & 11.616 \\
\hline $6-311 \mathrm{G}(\mathrm{d})$ & 71 & 137 & -2614.0691 & 2.054 & 11.035 & -2612.2540 & 2.053 & 10.981 & -2612.2540 & 2.045 & 10.546 \\
\hline $6-311 G(2 d)$ & 81 & 149 & -2614.0646 & 2.063 & 11.539 & -2612.2630 & 2.076 & 12.220 & -2612.2630 & 2.057 & 11.187 \\
\hline $6-311 \mathrm{G}(3 \mathrm{df})$ & 105 & 181 & -2614.0747 & 2.055 & 11.064 & -2612.3279 & 2.067 & 11.708 & -2612.3279 & 2.049 & 10.735 \\
\hline $6-311+\mathrm{G}$ & 69 & 133 & -2614.0093 & 2.065 & 11.602 & -2612.0873 & 2.061 & 11.422 & -2612.0873 & 2.068 & 11.796 \\
\hline $6-311+\mathrm{G}(\mathrm{d})$ & 79 & 145 & -2614.0698 & 2.057 & 11.184 & -2612.2552 & 2.056 & 11.147 & -2612.2552 & 2.048 & 10.692 \\
\hline $6-311+\mathrm{G}(2 \mathrm{~d})$ & 89 & 157 & -2614.0654 & 2.062 & 11.476 & -2612.2641 & 2.074 & 12.134 & -2612.2641 & 2.055 & 11.104 \\
\hline $6-311+G(3 d f)$ & 113 & 189 & -2614.0754 & 2.046 & 10.618 & -2612.3289 & 2.059 & 11.270 & -2612.3289 & 2.041 & 10.340 \\
\hline $6-311++\mathrm{G}$ & 72 & 136 & -2614.0094 & 2.065 & 11.625 & -2612.0877 & 2.062 & 11.453 & -2612.0877 & 2.069 & 11.825 \\
\hline $6-311++G(d)$ & 82 & 148 & -2614.0699 & 2.057 & 11.190 & -2612.2555 & 2.056 & 11.161 & -2612.2555 & 2.048 & 10.707 \\
\hline $6-311++\mathrm{G}(2 \mathrm{~d})$ & 92 & 160 & -2614.0655 & 2.062 & 11.456 & -2612.2644 & 2.074 & 12.105 & -2612.2644 & 2.055 & 11.076 \\
\hline $6-311++\mathrm{G}(3 \mathrm{df})$ & 116 & 192 & -2614.0755 & 2.046 & 10.604 & -2612.3291 & 2.059 & 11.270 & -2612.3291 & 2.041 & 10.335 \\
\hline $6-311++\mathrm{G}(3 \mathrm{df}, 3 \mathrm{pd})$ & 158 & 237 & -2614.0807 & 2.049 & 10.758 & -2612.3527 & 2.060 & 11.324 & -2612.3527 & 2.043 & 10.443 \\
\hline cc-pVDZ & 56 & 201 & -2614.0669 & 2.044 & 10.489 & -2612.2797 & 2.040 & 10.295 & -2612.2797 & 2.036 & 10.057 \\
\hline aug-cc-pVDZ & 86 & 233 & -2614.0740 & 2.039 & 10.232 & -2612.3027 & 2.050 & 10.798 & -2612.3027 & 2.038 & 10.186 \\
\hline cc-pVTZ & 115 & 300 & -2614.1610 & 2.049 & 10.775 & -2612.5012 & 2.056 & 11.116 & -2612.5012 & 2.040 & 10.252 \\
\hline aug-cc-pVTZ & 174 & 370 & -2614.1618 & 2.049 & 10.761 & -2612.5147 & 2.058 & 11.227 & -2612.5147 & 2.042 & 10.400 \\
\hline aug-cc-pVTZ with ECP & 174 & 370 & -53.0620 & 2.019 & 9.153 & -52.8973 & 2.036 & 10.074 & -52.8973 & 2.019 & 9.145 \\
\hline Mean value & & & & & 10.847 & & & 11.191 & & & 10.549 \\
\hline E.s.d. for mean value & & & & & 0.667 & & & 0.652 & & & 0.803 \\
\hline
\end{tabular}

aug-cc-pVTZ basis set, which we consider as the largest and therefore most reliable approximation. Apparently, it occurs that for the largest basis set the anisotropy of $\mathrm{Cl}$ atom is more efficient in the case of the $\mathrm{H}_{3} \mathrm{C}-\mathrm{Cl}$ system (with the only exception for MP2-SCF densities, for which in $\mathrm{F}_{3} \mathrm{C}-\mathrm{Cl}$ the $\chi$ parameter is larger by about $0.5 \%$ than that estimated for $\mathrm{H}_{3} \mathrm{C}-\mathrm{Cl}$ ). Note, however, that we consider the MP2-SCF densities as an approximation of the lowest reliability of those taken into account since these densities in fact are not consistent with equilibrium geometries estimated at the MP2 post-SCF level of calculations. Therefore, the significantly stronger X-bonds formed by $\mathrm{F}_{3} \mathrm{C}-\mathrm{Cl}$ as compared with $\mathrm{H}_{3} \mathrm{C}-\mathrm{Cl}$ [28], cannot be explained merely on the basis of larger anisotropy of $\mathrm{Cl}$ atom in the former. In this case, another mechanism must be responsible for the additional strengthening of the $\mathrm{X}$-bond, which may be connected with the charge transfer from Lewis base center into the inner region of Lewis acid center and not directly on the halogen atom $(\mathrm{Cl}$ in that case). This can be additionally supported by the fact that, according to the NBO analysis reported recently [27], the charge transfer occurs from the Lewis base center to the more remote parts of the halogen. In the case of $\mathrm{Br}$ derivatives, the values of $\chi$ are also similar for both 
Table 3 Numerical data for $\mathrm{F}_{3} \mathrm{CCl}$ molecule (energy given in hartrees)

\begin{tabular}{|c|c|c|c|c|c|c|c|c|c|c|c|}
\hline & \multirow[t]{2}{*}{ NBF } & \multirow[t]{2}{*}{ Primitives } & \multicolumn{3}{|l|}{ B3LYP } & \multicolumn{3}{|c|}{ MP2 (SCF density) } & \multicolumn{3}{|c|}{ MP2 (post-SCF density) } \\
\hline & & & $E_{\text {tot }}$ & $r_{2}$ & $\chi$ & $E_{\text {tot }}$ & $r_{2}$ & $\chi$ & $E_{\text {tot }}$ & $r_{2}$ & $\chi$ \\
\hline $3-21 G$ & 49 & 87 & -793.7719 & 1.908 & 9.038 & -792.1401 & 1.923 & 9.864 & -792.1401 & 1.916 & 9.459 \\
\hline $3-21+\mathrm{G}$ & 69 & 107 & -793.8822 & 1.931 & 10.351 & -792.2625 & 1.940 & 10.880 & -792.2625 & 1.939 & 10.774 \\
\hline $6-31 \mathrm{G}$ & 49 & 134 & -797.7084 & 1.939 & 10.774 & -796.0199 & 1.956 & 11.757 & -796.0199 & 1.946 & 11.228 \\
\hline $6-31 \mathrm{G}(\mathrm{d})$ & 79 & 164 & -797.8167 & 1.959 & 11.959 & -796.4311 & 1.941 & 10.910 & -796.4311 & 1.921 & 9.746 \\
\hline $6-31 G(2 d)$ & 109 & 194 & -797.8283 & 1.916 & 9.477 & -796.5604 & 1.946 & 11.182 & -796.5604 & 1.921 & 9.743 \\
\hline $6-31 G(3 d f)$ & 174 & 274 & -797.8582 & 1.925 & 10.009 & -796.7364 & 1.952 & 11.539 & -796.7364 & 1.924 & 9.961 \\
\hline $6-31+\mathrm{G}$ & 69 & 154 & -797.7337 & 1.932 & 10.414 & -796.0507 & 1.950 & 11.412 & -796.0507 & 1.945 & 11.170 \\
\hline $6-31+\mathrm{G}(\mathrm{d})$ & 99 & 184 & -797.8430 & 1.919 & 9.649 & -796.4613 & 1.936 & 10.605 & -796.4613 & 1.919 & 9.664 \\
\hline $6-31+G(2 d)$ & 129 & 214 & -797.8558 & 1.930 & 10.293 & -796.5882 & 1.952 & 11.515 & -796.5882 & 1.929 & 10.251 \\
\hline $6-31+G(3 d f)$ & 194 & 294 & -797.8668 & 1.922 & 9.825 & -796.7487 & 1.948 & 11.327 & -796.7487 & 1.922 & 9.816 \\
\hline $6-311 \mathrm{G}$ & 73 & 147 & -797.8475 & 1.938 & 10.762 & -796.1983 & 1.952 & 11.527 & -796.1983 & 1.948 & 11.291 \\
\hline $6-311 \mathrm{G}(\mathrm{d})$ & 98 & 177 & -797.9497 & 1.921 & 9.794 & -796.6607 & 1.933 & 10.432 & -796.6607 & 1.916 & 9.471 \\
\hline $6-311 G(2 d)$ & 123 & 207 & -797.9622 & 1.932 & 10.384 & -796.7610 & 1.951 & 11.494 & -796.7610 & 1.925 & 10.024 \\
\hline $6-311 G(3 d f)$ & 183 & 287 & -797.9806 & 1.932 & 10.408 & -796.9061 & 1.957 & 11.836 & -796.9061 & 1.932 & 10.396 \\
\hline $6-311+\mathrm{G}$ & 93 & 167 & -797.8619 & 1.930 & 10.296 & -796.2215 & 1.947 & 11.252 & -796.2215 & 1.944 & 11.077 \\
\hline $6-311+\mathrm{G}(\mathrm{d})$ & 118 & 197 & -797.9639 & 1.917 & 9.568 & -796.6818 & 1.931 & 10.357 & -796.6818 & 1.914 & 9.365 \\
\hline $6-311+\mathrm{G}(2 \mathrm{~d})$ & 143 & 227 & -797.9735 & 1.931 & 10.336 & -796.7764 & 1.950 & 11.415 & -796.7764 & 1.925 & 10.000 \\
\hline $6-311+G(3 d f)$ & 203 & 307 & -797.9915 & 1.919 & 9.682 & -796.9194 & 1.945 & 11.119 & -796.9194 & 1.919 & 9.667 \\
\hline cc-pVDZ & 74 & 203 & -797.8624 & 1.898 & 8.455 & -796.5239 & 1.914 & 9.383 & -796.5239 & 1.897 & 8.379 \\
\hline maug-cc-pVDZ & 94 & 223 & -797.8878 & 1.923 & 9.873 & -796.5520 & 1.932 & 10.408 & -796.5520 & 1.917 & 9.528 \\
\hline aug-cc-pVDZ & 119 & 253 & -797.8962 & 1.912 & 9.283 & -796.6177 & 1.939 & 10.829 & -796.6177 & 1.920 & 9.716 \\
\hline cc-pVTZ & 154 & 302 & -797.9995 & 1.911 & 9.187 & -796.9278 & 1.930 & 10.281 & -796.9278 & 1.906 & 8.923 \\
\hline maug-cc-pVTZ & 174 & 322 & -798.0042 & 1.924 & 9.970 & -796.9334 & 1.943 & 11.016 & -796.9334 & 1.919 & 9.634 \\
\hline aug-cc-pVTZ & 234 & 402 & -798.0064 & 1.921 & 9.764 & -796.9604 & 1.942 & 10.971 & -796.9604 & 1.919 & 9.676 \\
\hline aug-cc-pVTZ with ECP & 234 & 402 & -352.6805 & 1.892 & 8.134 & -352.1264 & 1.915 & 9.444 & -352.1264 & 1.893 & 8.186 \\
\hline Mean value & & & & & 9.907 & & & 10.910 & & & 9.886 \\
\hline E.s.d. for mean value & & & & & 0.777 & & & 0.672 & & & 0.795 \\
\hline
\end{tabular}

$\mathrm{H}_{3} \mathrm{C}-\mathrm{Br}$ and $\mathrm{F}_{3} \mathrm{C}-\mathrm{Br}$, this time, however, the values of $\chi$ obtained for the $\mathrm{F}_{3} \mathrm{C}-\mathrm{Br}$ system are slightly larger. Still, the differences are very small and can hardly explain significantly larger abilities of X-bond formation in the case of trifluoro derivatives. Clearly, $\mathrm{Br}$ atom is characterized by larger anisotropy than $\mathrm{Cl}$ atom. This was in fact expected since the larger atom is more susceptible to polarization.

In general, the values of $\chi$ estimated with the use of DFTB3LYP and MP2 (post-SCF densities) are rather similar. Clearly, the basis set size, or more precisely its construction including polarization and diffuse functions, affects the $\chi$ parameter much more effectively than the chemistry model itself. Undoubtedly, the presence of polarization and diffuse functions has the greatest influence on $\chi$. It is remarkable that the basis sets which are most saturated with polarization and diffuse functions give the results being in between those obtained for less saturated basis sets and the basis sets with no polarization and diffuse functions. This means that relatively smaller $\chi$ values were obtained when no polarization and diffuse functions were included in the basis set, and relatively larger $\chi$ values were obtained when basis sets partially saturated with polarization and diffuse functions were taken for calculations. Owing to this, the mean values of $\chi$ estimated for all basis sets (and for the given method) are similar to the $\chi$ values obtained for the largest basis sets. Nevertheless, for this reason, there is no clear tendency between, for instance, the number of basis functions or the number of primitives and the $\chi$ parameter.

In addition, for comparative reasons, we also provide the results of the effective core potential (ECP) approximation. The ECP was introduced instead of the core region of the halogen atom, whereas aug-cc-pVTZ basis was used to describe the remainder part of the system. Los Alamos ECP model was used in that case [48, 49]. It occurs that in all cases, the use of the ECP model decreases the values of $\chi$. This tendency is stronger in the case of the larger $\mathrm{Br}$ atom for which the impact of the core region on valence electrons is more effective than for the lighter $\mathrm{Cl}$ atom. 
Table 4 Numerical data for $\mathrm{F}_{3} \mathrm{CBr}$ molecule (energy given in hartrees)

\begin{tabular}{|c|c|c|c|c|c|c|c|c|c|c|c|}
\hline & \multirow[t]{2}{*}{ NBF } & \multirow[t]{2}{*}{ Primitives } & \multicolumn{3}{|l|}{ B3LYP } & \multicolumn{3}{|c|}{ MP2 (SCF density) } & \multicolumn{3}{|c|}{ MP2 (post-SCF density) } \\
\hline & & & $E_{\text {tot }}$ & $r_{2}$ & $\chi$ & $E_{\mathrm{tot}}$ & $r_{2}$ & $\chi$ & $E_{\text {tot }}$ & $r_{2}$ & $\chi$ \\
\hline $3-21 G$ & 59 & 117 & -2897.5793 & 2.026 & 9.508 & -2894.8907 & 2.044 & 10.492 & -2894.8907 & 2.030 & 9.725 \\
\hline $6-31 G$ & 60 & 165 & -2909.1006 & 2.060 & 11.342 & -2906.3114 & 2.090 & 12.966 & -2906.3114 & 2.071 & 11.948 \\
\hline $6-31 G(d)$ & 90 & 195 & -2909.3236 & 2.043 & 10.423 & -2906.8161 & 2.067 & 11.716 & -2906.8161 & 2.041 & 10.349 \\
\hline $6-31 G(2 d)$ & 120 & 225 & -2909.5014 & 2.027 & 9.542 & -2907.1167 & 2.067 & 11.731 & -2907.1167 & 2.032 & 9.823 \\
\hline $6-31 G(3 d f)$ & 185 & 305 & -2909.4163 & 2.033 & 9.903 & -2907.1723 & 2.070 & 11.865 & -2907.1723 & 2.037 & 10.117 \\
\hline $6-31+\mathrm{G}$ & 80 & 185 & -2909.1455 & 2.071 & 11.957 & -2906.3616 & 2.094 & 13.186 & -2906.3616 & 2.080 & 12.426 \\
\hline $6-31+\mathrm{G}(\mathrm{d})$ & 110 & 215 & -2909.3629 & 2.064 & 11.559 & -2906.8581 & 2.082 & 12.560 & -2906.8581 & 2.056 & 11.133 \\
\hline $6-31+\mathrm{G}(2 \mathrm{~d})$ & 140 & 245 & -2909.5340 & 2.043 & 10.406 & -2907.1498 & 2.078 & 12.320 & -2907.1498 & 2.044 & 10.463 \\
\hline $6-31+G(3 d f)$ & 205 & 325 & -2909.4287 & 2.052 & 10.912 & -2907.1878 & 2.082 & 12.563 & -2907.1878 & 2.051 & 10.847 \\
\hline $6-311 \mathrm{G}$ & 91 & 188 & -2911.7347 & 2.077 & 12.268 & -2909.0447 & 2.105 & 13.767 & -2909.0447 & 2.088 & 12.860 \\
\hline $6-311 G(d)$ & 116 & 218 & -2911.8698 & 2.055 & 11.101 & -2909.5060 & 2.075 & 12.168 & -2909.5060 & 2.048 & 10.698 \\
\hline $6-311 \mathrm{G}(2 \mathrm{~d})$ & 141 & 248 & -2911.8756 & 2.073 & 12.031 & -2909.5887 & 2.104 & 13.710 & -2909.5887 & 2.067 & 11.739 \\
\hline $6-311 \mathrm{G}(3 \mathrm{df})$ & 201 & 328 & -2911.8986 & 2.059 & 11.322 & -2909.7415 & 2.083 & 12.603 & -2909.7415 & 2.051 & 10.867 \\
\hline $6-311+\mathrm{G}$ & 111 & 208 & -2911.7478 & 2.067 & 11.733 & -2909.0667 & 2.093 & 13.129 & -2909.0667 & 2.078 & 12.305 \\
\hline $6-311+\mathrm{G}(\mathrm{d})$ & 136 & 238 & -2911.8821 & 2.051 & 10.841 & -2909.5241 & 2.068 & 11.793 & -2909.5241 & 2.042 & 10.372 \\
\hline $6-311+\mathrm{G}(2 \mathrm{~d})$ & 161 & 268 & -2911.8860 & 2.061 & 11.384 & -2909.6028 & 2.091 & 13.012 & -2909.6028 & 2.054 & 11.044 \\
\hline $6-311+G(3 d f)$ & 221 & 348 & -2911.9084 & 2.048 & 10.695 & -2909.7533 & 2.073 & 12.031 & -2909.7533 & 2.040 & 10.272 \\
\hline cc-pVDZ & 83 & 279 & -2911.7962 & 2.045 & 10.552 & -2909.3944 & 2.068 & 11.768 & -2909.3944 & 2.040 & 10.269 \\
\hline aug-cc-pVDZ & 128 & 329 & -2911.8304 & 2.038 & 10.146 & -2909.4905 & 2.064 & 11.588 & -2909.4905 & 2.038 & 10.146 \\
\hline cc-pVTZ & 163 & 405 & -2911.9915 & 2.053 & 10.975 & -2909.9030 & 2.075 & 12.180 & -2909.9030 & 2.042 & 10.389 \\
\hline aug-cc-pVTZ & 243 & 505 & -2911.9984 & 2.047 & 10.655 & -2909.9410 & 2.072 & 12.022 & -2909.9410 & 2.039 & 10.195 \\
\hline aug-cc-pVTZ with EPC & 243 & 505 & -350.8983 & 2.023 & 9.351 & -350.3233 & 2.055 & 11.076 & -350.3233 & 2.022 & 9.311 \\
\hline Mean value & & & & & 10.846 & & & 12.284 & & & 10.786 \\
\hline E.s.d. for mean value & & & & & 0.829 & & & 0.806 & & & 0.935 \\
\hline
\end{tabular}

\section{Conclusions}

The search through CSD was performed and the distances in contacts of $\mathrm{X} \cdots \mathrm{N}, \mathrm{O}, \mathrm{X} \cdots \mathrm{H}(\mathrm{N}, \mathrm{O})$, and $\mathrm{X} \cdots \mathrm{C}$ were collected together with the information on spatial arrangement of the interacting fragments. A detailed statistical analysis of the data obtained in the CSD search shows that the shape of the halogen atom cannot be estimated merely on the basis of interatomic distances in crystals. It occurs that the virtual shape of the halogen atom estimated in such a way strongly depends on the type of interacting center.

Since intermolecular interactions are not a sufficient source of information about the anisotropy of the halogen atom, an alternative way in which this physical property can be quantified was proposed. The analysis of electron distribution was performed within the framework of QTAIM for $\mathrm{H}_{3} \mathrm{C}-\mathrm{X}$ and $\mathrm{F}_{3} \mathrm{C}-\mathrm{X}(\mathrm{X}=\mathrm{Cl}, \mathrm{Br})$. Densities from DFT and MP2 methods and several different basis sets were investigated. It was shown that the polar flattering of the halogen atom can be measured and that it is equal to about 10 and $11 \%$ for $\mathrm{Cl}$ and $\mathrm{Br}$, respectively, when estimated in the valence region of the $\mathrm{X}$ atom.
It was also shown that the method used in calculations rather does not affect the anisotropy. The basis set used is much more important in this respect. In particular, the number of polarization and diffuse functions is decisive. However, no general relation between the degree of anisotropy and the size of basis set was found.

Acknowledgments Calculations by means of the Gaussian 09 set of codes were carried out in Wrocław Centre for Networking and Supercomputing (http://www.wcss.wroc.pl). Access to HPC machines and licensed software is gratefully acknowledged.

Open Access This article is distributed under the terms of the Creative Commons Attribution License which permits any use, distribution, and reproduction in any medium, provided the original author(s) and the source are credited.

\section{References}

1. Metrangolo P, Neukirch H, Pilati T, Resnati G (2005) Acc Chem Res 38:386

2. Aakeroy CB, Fasulo M, Schultheiss N, Desper J, Moore C (2007) J Am Chem Soc 129:13772 
3. Corradi E, Meille SV, Messina MT, Metrangolo P, Resnati G (2000) Angew Chem 112:1852

4. Corradi E, Meille SV, Messina MT, Metrangolo P, Resnati G (2000) Angew Chem Int Ed 39:1782

5. Metrangolo P, Resnati G (2001) Chem Eur J 7:2511

6. Fox DB, Liantonio R, Metrangolo P, Pilati T, Resnati G (2004) J Fluor Chem 125:271

7. Metrangolo P, Resnati G, Pilati T, Liantonio R, Meyer F (2007) J Polym Sci Part A Polym Chem 45:1

8. Cincic D, Friscic T, Jones W (2008) Chem Eur J 14:747

9. Cincic D, Friscic T, Jones W (2008) J Am Chem Soc 130:7524

10. Metrangolo P, Meyer F, Pilati T, Resnati G, Terraneo G (2008) Angew Chem 120:6206

11. Metrangolo P, Meyer F, Pilati T, Resnati G, Terraneo G (2008) Angew Chem Int Ed 47:6114

12. Derossi S, Brammer L, Hunter CA, Ward DM (2009) Inorg Chem 48:1666

13. Shirman T, Arad T, van der Boom ME (2010) Angew Chem 122:938

14. Shirman T, Arad T, van der Boom ME (2010) Angew Chem Int Ed 49:926

15. Voth AR, Hays FA, Ho PS (2007) Proc Natl Acad Sci 104:6188

16. Auffinger P, Hays FA, Westhof E, Ho PS (2004) Proc Natl Acad Sci 101:16789

17. Politzer P, Murray JS, Clark T (2010) Phys Chem Chem Phys 12:7748

18. Braga D, Desiraju GR, Miller JS, Orpen AG, Price SL (2002) CrystEngComm 4:500

19. Lu Y, Shi T, Wang Y, Yang H, Yan X, Luo X, Jiang H, Zhu W (2009) J Med Chem 52:2854

20. Nguyen LH, Horton PN, Hursthouse BM, Legon AC, Bruce DW (2004) J Am Chem Soc 126:16

21. Weinhold F, Landis CR (2005) Valency and bonding - a natural bond orbital donor-acceptor perspective. Cambridge University Press, Cambridge

22. Clark T, Hennemann M, Murray JS, Politzer P (2007) J Mol Model 13:291

23. Murray JS, Riley KE, Politzer P, Clark T (2010) Aust J Chem 63:1598
24. Legon AC (2010) Phys Chem Chem Phys 12:7736

25. Feng G, Evangelisti L, Gasparini N, Caminati W (2012) Chem Eur J 18:1364

26. Alkorta I, Sanchez-Sanz G, Elguero J, Del Bene JE (2012) J Phys Chem A 116:2300

27. Jablonski M, Palusiak M (2012) J Phys Chem A 116:2322

28. Palusiak M (2010) J Mol Struct: THEOCHEM 945:89

29. Lommerse JPM, Stone AJ, Taylor R, Allen FH (1996) J Am Chem Soc 118:3108

30. Riley KE, Hobza P (2008) J Chem Theory Comput 4:232

31. Nyburg SC, Faerman CH (1985) Acta Crystallogr B 41:274

32. Alen FH (2002) Acta Crystallogr Sect B 58:380

33. Price SL, Stone AJ, Lucas J, Rowland RS, Thornley AE (1994) J Am Chem Soc 116:4910

34. Grabowski SJ (2011) J Phys Chem A 115:12340

35. Wheatleya RJ, Gopal AA (2012) Phys Chem Chem Phys 14:2087

36. Jeziorski B, Moszynski R, Ratkiewicz A, Rybak S, Szalewicz K, Williams HL (1993) In: Clementi E (ed) Methods and techniques in computational chemistry: METECC-94, vol B. Cagliari, STEF, p 79

37. Frisch MJ, Trucks GW, Schlegel HB, Scuseria GE et al (2009) Gaussian 09, Revision A 0.2. Gaussian 09 Inc, Wallingford

38. Becke AD (1993) J Chem Phys 98:5648

39. Lee C, Yang W, Parr RG (1998) Phys Rev B 37:785

40. Møller C, Plesset MS (1934) Phys Rev 46:618

41. Pople JA, Binkley JS, Seeger R (1976) Int J Quantum Chem Symp 10:1

42. Gaussian 09 manual. http://www.gaussian.com/g_tech/g_ur/refs. htm. Accessed Nov 2012

43. Biegler-Konig FW, Bader RFW, Tang TH (1982) J Comput Chem 3:317

44. Biegler-Konig FW (2000) AIM2000. University of Applied Sciences, Bielefeld

45. Bondi A (1964) J Phys Chem 68:441

46. Rowland RS, Taylor R (1996) J Phys Chem 100:7384

47. Dunitz JD, Taylor R (1997) Chem Eur J 3:89

48. Hay PJ, Wadt WR (1985) J Chem Phys 82:270

49. Hay PJ, Wadt WR (1985) J Chem Phys 82:299 